\title{
RESEARCH
}

Open Access

\section{Axillary lymph node status in BIRADS 4-5 female patients: can shear wave and strain ultrasound elastography help?}

Dalia Salaheldin Elmesidy ${ }^{1,2^{*}}$ (D), Menna Allah Gaber Ahmed Mohamed Eissa', Soha Talaat Hamed ${ }^{1}$, Omar Zakaria Youssef ${ }^{3}$, Omnia Mokhtar Nada ${ }^{2,4}$ and Lamiaa Mohamed Bassam Hashem,2

\begin{abstract}
Background: The status of axillary nodes is a determining factor of management and prognosis for patients having a recent diagnosis of breast cancer. Axillary nodes are usually evaluated by ultrasonography (US) and biopsy, if indicated. Ultrasound-guided sampling and intraoperative or sentinel nodal sampling are available options, however, are invasive and hold risks of potential complications, calling for reliable, non-invasive axillary imaging. In the current prospective study, we assessed the performance of shear wave (SWE) and strain (SE) ultrasound elastography regarding preoperative axillary assessment. Sixty axillary nodes from 60 patients (age 28-65 years, mean $49.88 \pm 7.61$ SD) were included, all scoring BIRADS 4-5 on sonomammography.

Results: For US, sensitivity, specificity, positive predictive value (PPV), negative predictive value (NPV), and accuracy were $100 \%, 66.67 \%, 84.78 \%, 100 \%$, and $88.33 \%$, respectively. Cortical thickness and vascularity were the most sensitive. For qualitative SWE, indices were $76.92 \%, 80.95 \%, 88.24 \%, 65.38 \%$ and $78.33 \%$, respectively. Calculated cutoff for Emax was 59.3 and for Eratio was 4.56, giving statistical indices of 76.9\%, 90.5\%, 93.75\%, 67.86\%, and 81.67\% for Emax and 76.9\%, 100\%, 100\%, 70\% and 85\% respectively for Eratio. Both Emax and Eratio were greater for malignant (Emax $81.77 \pm$ 1.904, Eratio $8.95 \pm 5.69$ ) than for benign nodes (Emax $37.59 \pm 33.37$, Eratio $2.5 \pm 1.37)(P$ values $<0.001$ ). For qualitative SE, sensitivity and specificity were $92.31 \%$ and $57.14 \%$, while PPV, NPV, and accuracy were $80 \%$ each ( $P$ values $<0.001$ ). The calculated cut-off value for SR was 3.85 , giving indices of $87.2 \%, 76.2 \%$, $76.19 \%, 87.18 \%$ and $83.33 \%$ respectively.
\end{abstract}

Conclusion: Adding elastography evaluation to conventional US positively impacts the specificity and accuracy of the preoperative axillary nodal status assessment in patients having newly diagnosed breast cancer.

Keywords: Axillary nodes, Shear wave elastography, Strain elastography, Breast cancer

\footnotetext{
* Correspondence: daliamsd@windowslive.com

'Department of Diagnostic and Interventional Radiology, Faculty of

Medicine, Cairo University, Cairo, Egypt

${ }^{2}$ Department of Diagnostic and Interventional Radiology, Baheya Foundation,

Cairo, Egypt

Full list of author information is available at the end of the article
}

\section{Springer Open}

(ㅇ The Author(s). 2021 Open Access This article is licensed under a Creative Commons Attribution 4.0 International License, which permits use, sharing, adaptation, distribution and reproduction in any medium or format, as long as you give appropriate credit to the original author(s) and the source, provide a link to the Creative Commons licence, and indicate if changes were made. The images or other third party material in this article are included in the article's Creative Commons licence, unless indicated otherwise in a credit line to the material. If material is not included in the article's Creative Commons licence and your intended use is not permitted by statutory regulation or exceeds the permitted use, you will need to obtain permission directly from the copyright holder. To view a copy of this licence, visit http://creativecommons.org/licenses/by/4.0/. 


\section{Background}

Accurate preoperative assessment of the axillary nodal status in cases with recently discovered breast cancer is a crucial part of its management which involves staging, plan of treatment, and prognosis [1]. Although definitive pathologic diagnosis is invaluable for those patients, radiologic imaging represents the primary way used for staging [2]. For pathological axillary lymphadenopathy, ultrasound (US) and fine-needle aspiration are commonly used for preoperative assessment. Yet, as a result of the moderate sensitivity and false-negative results, this can lead to unessential sentinel nodal sampling, which can cause related upper limb morbidities. Therefore, a need has emerged for a non-invasive tool that can accurately stage axillary lymph nodes preoperatively [3].

Elastography is one of the advances of US which has a potential to differentiate malignant from benign tissue by measuring its elasticity. For breast US, it can be either strain elastography (SE) or shear wave elastography (SWE) [1]. Both exploit the fact that malignant tissues are usually stiffer than benign ones, and thus, elastography can be utilized to ameliorate the specificity of US diagnosis [3]. Strain elastography relies on the operating hand where it utilizes freehand compression to estimate elasticity of tissues [1]. On the contrary, SWE gives absolute elasticity quantification where qualitative analysis is done using colour-coded elastography maps that are obtained in real time, simultaneously with b-mode US images, analyzing impulses generated before and after automatically produced rhythmic vertical compressive waves [4]. Quantitative analysis is done by calculating both Emax (maximum elasticity calculated using pressure wave velocity in the examined region) and Eratio (ratio between nodal mean elasticity and its surroundings), where higher values are generally noted with stiffer/malignant lesions [5].

In this study, we evaluated the impact of adding US elastography (SWE or SE) to the preoperative evaluation of the axillary nodal status in female patients with recently diagnosed breast cancer, having a Breast Imaging Reporting Database System Score (BIRADS) score of 4 or 5 on sonomammography (SMG). We compared its results to those of conventional US, where the final histopathology served as the standard of reference.

\section{Methods}

\section{Study population and their inclusion and exclusion criteria}

This prospective study included 60 axillary lymph nodes from 60 female patients with ages ranging from 28 to 65 years (mean 49.88 years $\pm 7.61 \mathrm{SD}$ ), who presented to our institution during the time period from December 2018 to May 2019. All participating patients had breast lesions scoring BIRADS 4 or 5 on SMG, and the most suspicious node on the ipsilateral side of the breast lesion was chosen to be included in the study. The most suspicious node was chosen based on its US criteria, mainly those with focal cortical thickening, effaced hilar fat, non-ovoid shape and deranged hilar vascularity. All patients with BIRADS category 1, 2 or 3 lesions were excluded from participation. We also excluded those who were previously given neoadjuvant chemotherapy or any treatment that may affect the results of the study.

\section{Demographic data and history taking}

Patients provided informed written consents for participation, and our institutional ethical committee approval was obtained. Thorough demographic and clinical history taking were done (including name, age, marital status, offsprings, residence, phone number, diagnosis, illness duration, family history and history of previous illness). All patients underwent axillary b-mode US, SE and SWE. Examinations were performed using GE LOGIQ E9 XD clear 2.0 US scanner linear array electronic probes.

Examinations were performed and interpreted conjointly by two consultant radiologists, having more than 10 years of experience in the field of breast imaging. The results of each modality were correlated to those of final histopathology which served as a reference standard.

\section{Conventional US imaging and interpretation}

To perform the examinations, each patient was put in the oblique supine position with her ipsilateral hand placed behind the head so that her arm was in abduction and external rotation.

For conventional US, both gray scale and power/color Doppler were performed using a high-frequency linear transducer, scanning all nodes in orthogonal planes. To analyze US images, each node was assessed as regards its shape (whether ovoid or non-ovoid), presence of cortical thickening (considering a cortex measuring $>3 \mathrm{~mm}$ as thickened), and whether this thickening is diffuse, focal, or forming an irregular mass. Nodes were also evaluated regarding their fatty hila (whether central, eccentric, effaced or not preserved) and their vascularity (whether hilar or non-hilar). Each node was classified as benign, indeterminate or malignant blinded to histopathology results.

\section{Elastography (SWE and SE) imaging and interpretation} After US, both SE and SWE were done by putting the transducer over the examined node, utilizing contact gel and generating pressure waves (manually in SE and automatically in SWE). The patient was instructed to hold her breath for 10 to $20 \mathrm{~s}$ until the image stabilized. The built-in box was set in a form that it included the region of interest (ROI) of the examined node and adjacent normal tissue, followed by mild axial compression 
Table 1 Relation between the combined US criteria results and final pathology results

\begin{tabular}{|c|c|c|c|c|c|c|}
\hline & & \multicolumn{5}{|c|}{ Final pathology } \\
\hline & & \multicolumn{2}{|c|}{ Malignant } & \multicolumn{2}{|l|}{ Benign } & \multirow[t]{2}{*}{$P$ value } \\
\hline & & Number & $\%$ & Number & $\%$ & \\
\hline \multirow{2}{*}{$\begin{array}{l}\text { Combined US } \\
\text { criteria results }\end{array}$} & Malignant & 39 & $100 \%$ & 7 & $33.3 \%$ & \multirow[t]{2}{*}{$<0.001$} \\
\hline & Benign & 0 & $0 \%$ & 14 & $66.7 \%$ & \\
\hline
\end{tabular}

to the examined node until the pressure index reached 3 or 4 and lasted for 2 or $3 \mathrm{~s}$ in a stable manner.

$S E$ was done by performing manual, repeated compression and decompression in a maintained frequency over the region of interest. It gave a qualitative colorcoded map of the relative stiffness of tissues, ranging from red (lowest stiffness) to blue (highest stiffness). A ROI was put on the stiffest area of the examined node, and another ROI having the same size and on the same level was put in the surrounding axillary fat in order to calculate the strain ratio (SR).

For $S W E$, the pressure waves were produced automatically without the need for manual compression. This provided a semi-transparent map of color for stiffness of tissues that ranged from blue (lowest stiffness) to red (highest stiffness), and this was superimposed on the gray scale image. Numerical values for the velocity of the pressure wave in the examined region were also provided, automatically calculating the maximum elasticity value in kilopascals (Emax). A ROI was put on the stiffest part of the examined node and a similar one, having the same size, was placed at the same level in the adjacent fat, in order to calculate the ratio between the mean value of elasticity in the node of interest to that in the surrounding fat. Finally, we saved the image with the best quality and least artifacts to include in the study.

\section{Color-coded map scoring}

To analyze elastography images, the color-coded map of each examined node was evaluated using a modulated system of scoring, based on the percentage of relatively stiffer areas (areas of cortical hypoechogenicity) that scales from 1 to 4 depending on the nodal elastogram pattern, as follows:

- Score 1: Blue areas in case of SWE or red areas in case of SE occupying nearly all of the cortex
- Score 2: Red areas in case of SWE or blue areas in case of SE occupying < $50 \%$ of the cortex

- Score 3: Red areas in case of SWE or blue areas in case of SE occupying $>50 \%$ of the cortex

- Score 4: Red areas in case of SWE or blue area in case of SE occupying nearly all of the cortex

Nodes scoring 1 or 2 were considered as benign, whereas those scoring 3 or 4 were considered as metastatic. The cut-off values for SR (in case of SE) and for both Emax and Eratio (in case of SWE) were also calculated.

\section{Statistical analysis}

Finally, the blinded results for US, SE and SWE (qualitative analysis, SR, Emax and Eratio) were correlated to those of pathology using the Statistical Package for the Social Sciences, where quantitative data was expressed as mean, standard deviation (SD), median, minimum and maximum. Qualitative data was expressed as frequency and relative frequency. Comparisons between quantitative variables were done using the MannWhitney test (non-parametric). While for comparing qualitative data, Chi square $(x 2)$ test was performed. Exact test was used instead when the expected frequency was less than 5. Standard diagnostic indices (sensitivity, specificity, PPV, NPV and efficacy) were calculated, and receiver operating characteristics curve (ROC curve) with area under curve (AUC) analysis was performed to detect the best cut-off value of different parameters for malignancy detection, while logistic regression was done to predict malignancy by combination of US and elastography. $P$ values less than 0.05 were considered statistically significant.

\section{Results}

This prospective study included 60 axillary nodes from 60 female patients (with ages ranging from 28 to 65

Table 2 Relation of the results of colour-coded map scoring of SWE (qualitative analysis) and those of final pathology

\begin{tabular}{|c|c|c|c|c|c|c|}
\hline & & \multicolumn{5}{|c|}{ Final pathology } \\
\hline & & \multicolumn{2}{|c|}{ Malignant } & \multicolumn{2}{|l|}{ Benign } & \multirow[t]{2}{*}{$P$ value } \\
\hline & & Number & $\%$ & Number & $\%$ & \\
\hline \multirow{2}{*}{$\begin{array}{l}\text { Color map } \\
\text { score }\end{array}$} & Malignant & 30 & $76.9 \%$ & 4 & $19 \%$ & \multirow[t]{2}{*}{$<0.001$} \\
\hline & Benign & 9 & $23.1 \%$ & 17 & $81 \%$ & \\
\hline
\end{tabular}


Table 3 Lymph node distribution according to Emax and Eratio values

\begin{tabular}{|c|c|c|c|c|c|c|c|c|c|c|c|}
\hline & \multicolumn{10}{|c|}{ Final pathology } & \multirow[t]{3}{*}{$P$ value } \\
\hline & \multicolumn{5}{|l|}{ Benign } & \multicolumn{5}{|c|}{ Malignant } & \\
\hline & Number & Mean & SD & Minimum & Maximum & Number & Mean & SD & Minimum & Maximum & \\
\hline Emax & 21 & 37.59 & 24.08 & 8 & 115 & 39 & 81.77 & 33.37 & 27.5 & 156 & $<0.001$ \\
\hline Eratio & 21 & 2.5 & 1.37 & 0.7 & 4.5 & 39 & 8.95 & 5.69 & 0.56 & 24.8 & $<0.001$ \\
\hline
\end{tabular}

years, mean $49.88 \pm 7.61 \mathrm{SD}$ ) having lesions categorized as BIRADS 4 or 5 on SMG. Final pathology revealed that 21 out of the examined 60 nodes were not metastatic, while 39 were metastatic.

\section{Analysis of axillary nodes according to conventional US}

To analyze nodal b-mode US images, the following were studied:

1. The distribution of nodes according to their shape (ovoid/non-ovoid) where 40 out of 60 examined nodes were ovoid (66.7 \%) and 20 were non-ovoid (33.3\%).

Considering an 'ovoid shape' as a benign descriptor and 'non-ovoid' as a malignant one, the calculated sensitivity, specificity, PPV, NPV and accuracy were $51.28 \%$, $100 \%, 100 \%, 52.5 \%$ and $68.33 \%$ respectively, with a significant $P$ value $<0.001$

2. The distribution of nodes according to the presence of fatty hila (central/effaced/eccentric/totally infiltrated), where 31 out of the examined 60 nodes had central hila (51.7\%), 13 had effaced hila (21.7\%), 8 had eccentric hila (13.3\%), and 8 had totally infiltrated (non-preserved) hila (13.3\%).

Considering a 'central hilum' as a benign descriptor and 'effaced', 'eccentric' or 'totally infiltrated' hila as malignant ones, sensitivity, specificity, PPV, NPV and accuracy were $71.79 \%, 95.24 \%, 96.55 \%, 64.52 \%$ and $80 \%$, respectively, with significant $P$ value $<0.001$.

3. The distribution of nodes according to the presence of cortical thickening where by ROC curve analysis, the calculated cut-off value for cortical thickness that can differentiate between benign and malignant nodes was $3 \mathrm{~mm}$. Those with thickened cortexes were then distributed according to the shape of cortical thickening, into 'diffuse', 'focal', or 'thickening forming an irregular mass'.

It was found that 15 out of the examined 60 nodes had no cortical thickening (25\%), 26 had diffuse thickening (43.3\%), 15 had focal thickening (25\%), and 4 had thickening forming an irregular mass (6.7\%).

Considering 'no cortical thickening' as a benign descriptor and 'diffuse', 'focal' or 'irregular mass formation' as malignant ones, sensitivity, specificity, PPV, NPV and accuracy were 100\%, 71.4\%, 86.67\%, $100 \%$ and $90 \%$ respectively, with a significant $P$ value $<0.001$.

4. The distribution of nodes according to vascularity (hilar/non-hilar) where 27 out of the examined 60 nodes had hilar vascularity (45\%), and 33 had nonhilar vascularity (55\%).

When considering 'hilar vascularity' as a benign descriptor and 'non-hilar vascularity' as a malignant one, sensitivity, specificity, PPV, NPV and accuracy were $79.49 \%, 90.48 \%, 93.94 \%, 70.37 \%$ and $83.33 \%$ respectively, with significant $P$ value $<0.001$.

\section{The distribution of nodes according to all combined US criteria}

Considering all the US criteria combined together, nodes were classified as 'benign', 'indeterminate' and 'malignant', where 14 out of the examined 60 nodes (23.3\%) were diagnosed by US as benign, 23 (38.3\%), as indeterminate and 23 as malignant (38.3\%). The indeterminate and the malignant nodes were added together and all considered as suspicious. Therefore, 46 out of the examined 60 nodes were considered by US as suspicious (malignant), out of which 7 were proved to be benign by final pathology (false positive).

The calculated sensitivity, specificity, PPV, NPV and accuracy were $100 \%, 66.67 \%, 84.78 \%, 100 \%$ and $88.33 \%$ respectively, with significant $P$ value $<0.001$ (Table 1).

\section{Analysis of axillary nodes according to SWE The distribution of nodes according to the colour-coded map score of SWE (qualitative analysis)}

Fifteen out of the examined 60 nodes had a score of 1 (25\%) (almost all blue or green), 11 had a score of 2 (18.3\%) (blue > 50\%), 19 had a score of $3(31.7 \%)$ 


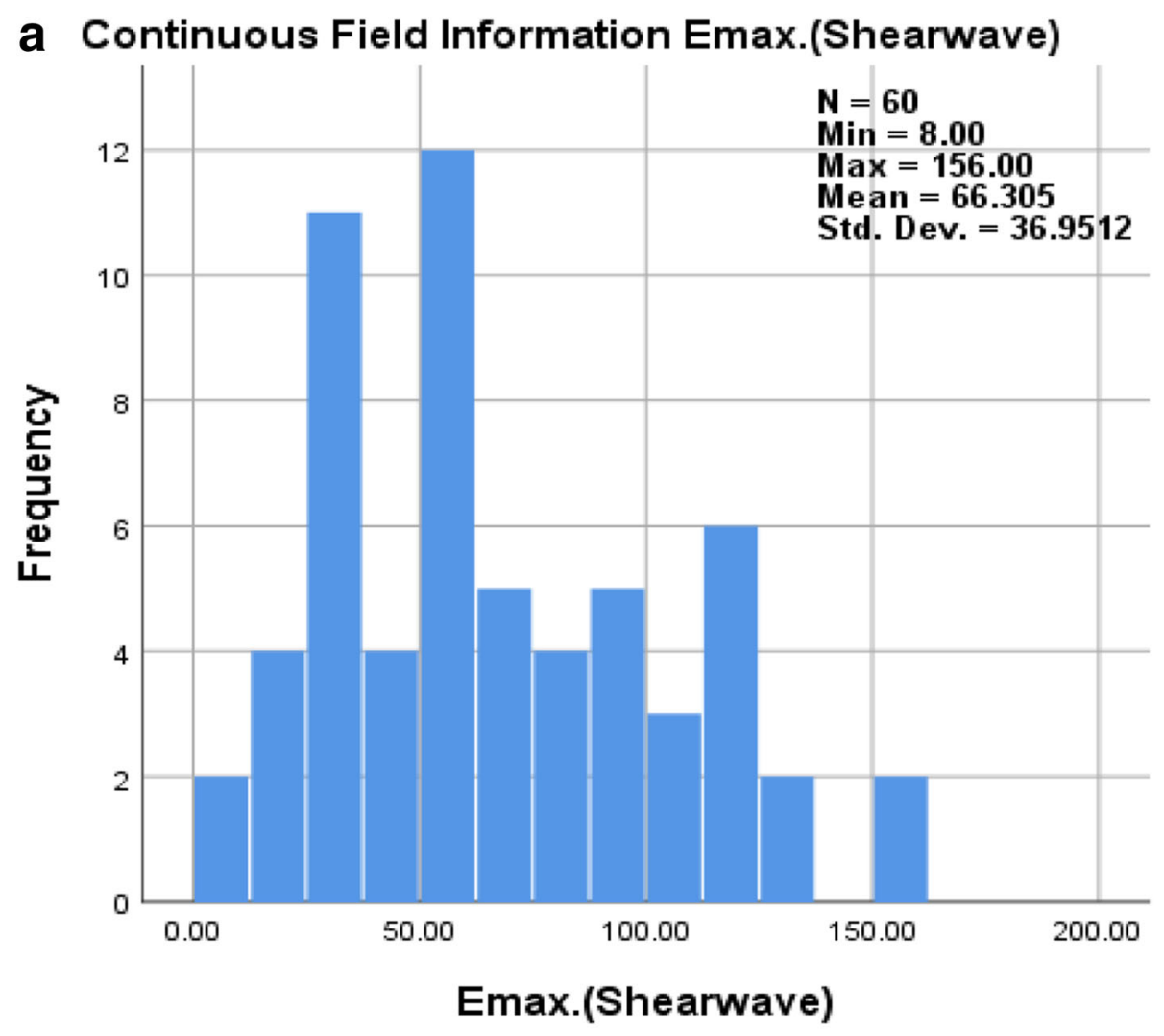

b Independent-Samples Mann-Whitney U Test FINAL PATHOLOGY

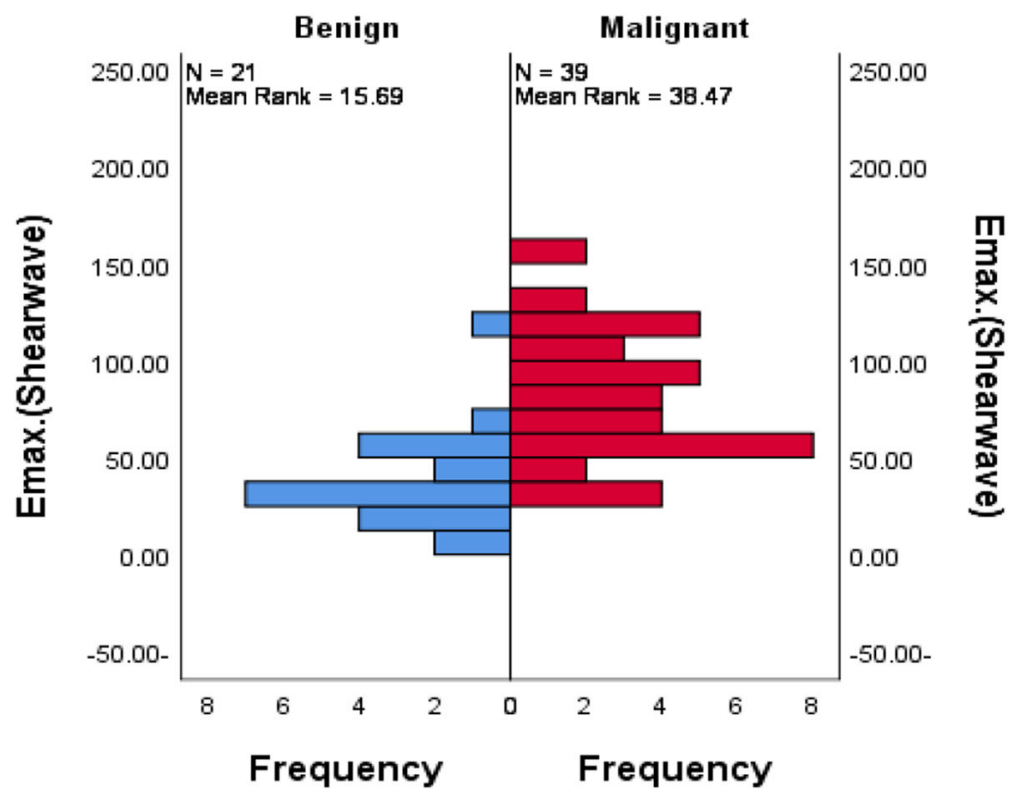

Fig. 1 a Distribution of Emax values for the examined nodes. $\mathbf{b}$ Distribution of Emax values for benign and malignant nodes 


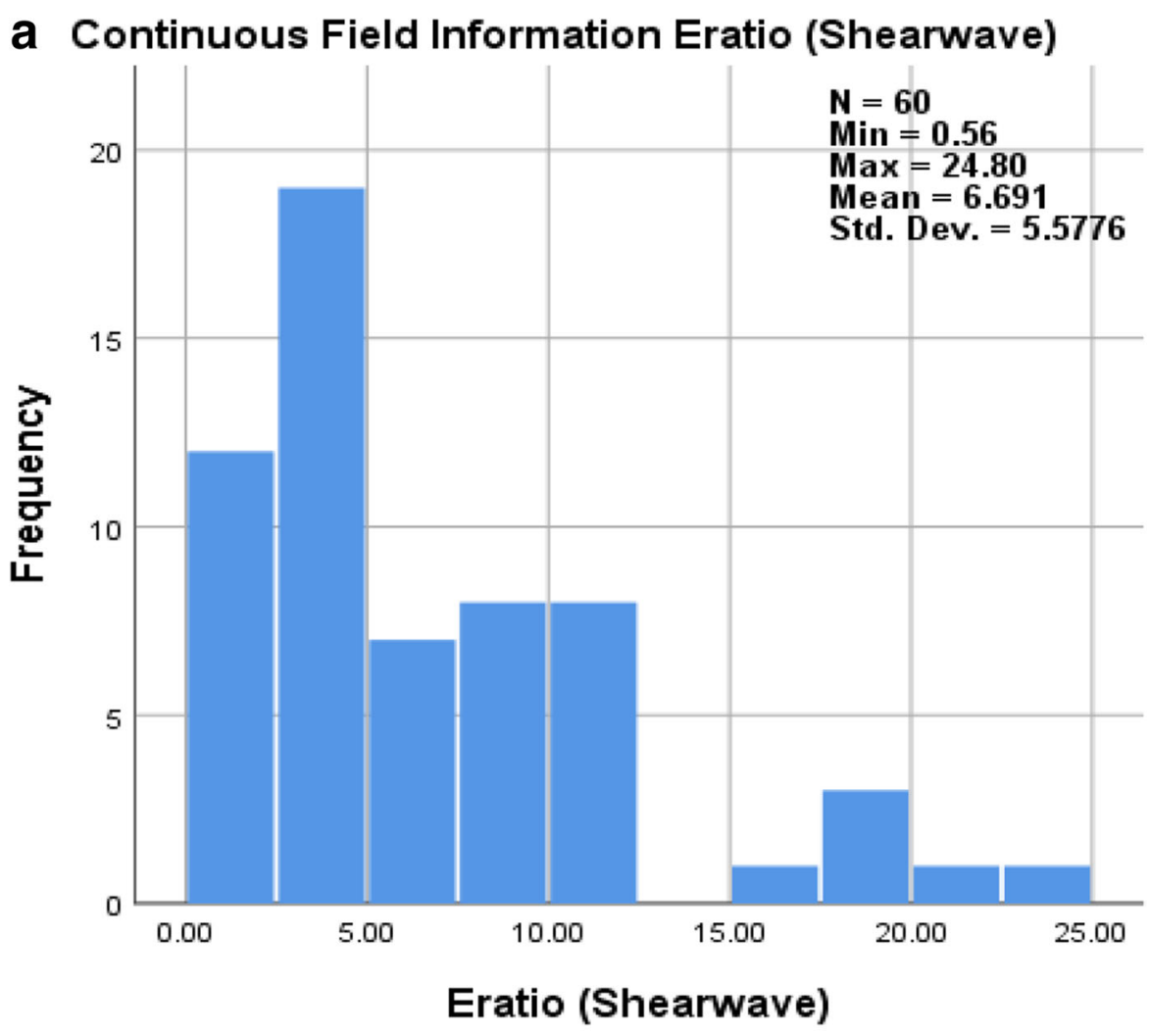

b Independent-Samples Mann-Whitney U Test FINAL PATHOLOGY

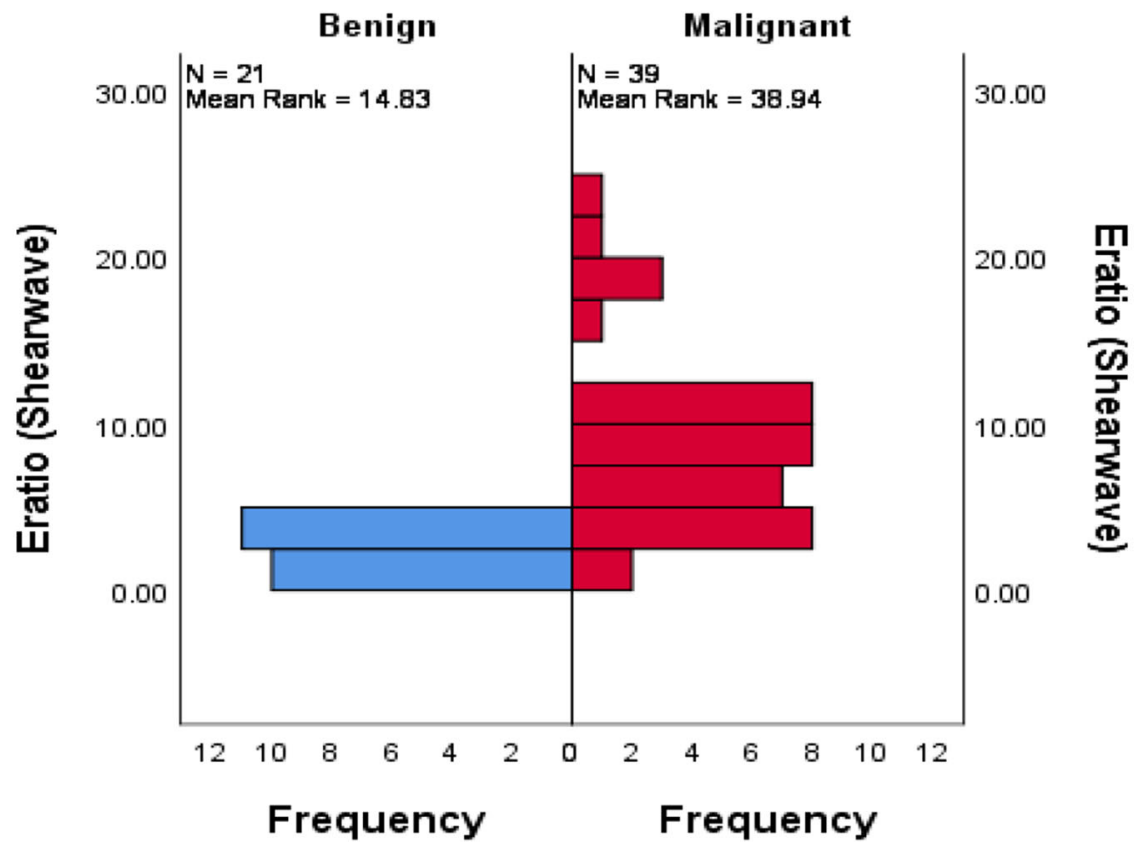

Fig. $\mathbf{2}$ a Distribution of Eratio values for the examined nodes. $\mathbf{b}$ Distribution of Eratio values for benign and malignant nodes 


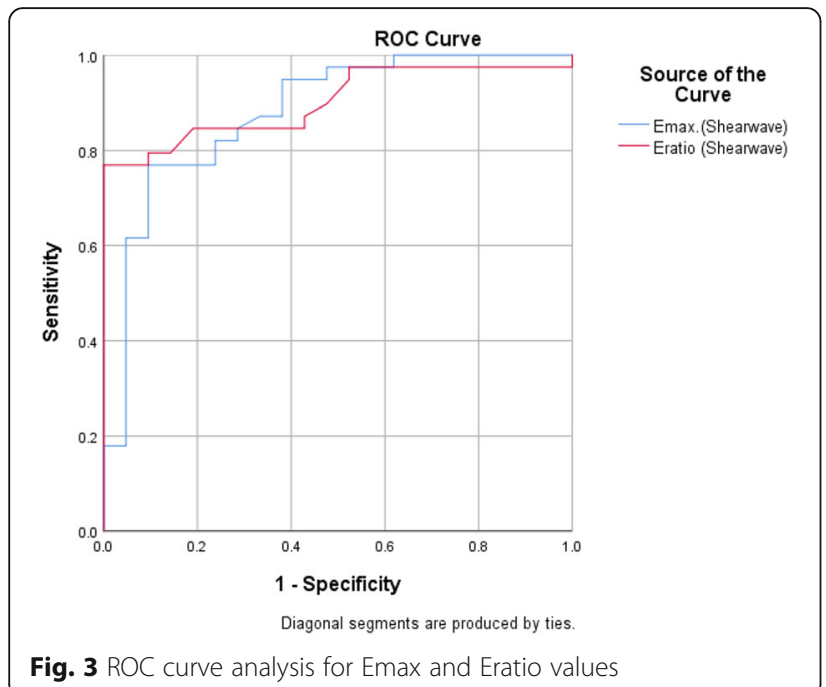

(red > 50\%) and 15 had a score of 4 (25\%) (almost all red). Considering scores 1 and 2 as benign descriptors and scores 3 and 4 as malignant ones, sensitivity, specificity, PPV, NPV and accuracy were $76.92 \%, 80.95 \%, 88.24 \%, 65.38 \%$ and $78.33 \%$ respectively, for the results of colour-coded map scoring correlated to those of final pathology, having a significant $P$ value $<0.001$ (Table 2).

\section{The distribution of nodes according to maximum elasticity (Emax) and elasticity ratio (Eratio) values (Table 3)}

The obtained Emax values for all nodes, ranged from 8 to $156 \mathrm{Kpa}$ (mean $66.3 \pm 36.95$ ) (Fig. 1a). It was noticed that the mean Emax value for malignant nodes (mean $81.77 \pm 1.904)$ was significantly greater than that for benign nodes (mean $37.59 \pm 33.37)(P$ value $<0.001)$ (Fig. 1b).

The obtained Eratio values for all nodes, ranged from 0.56 to 24.8 (mean $6.69 \pm 5.58$ ) (Fig. 2a). It was found that the mean Eratio value for malignant nodes (mean $8.95 \pm 5.69$ ) was significantly greater than that for benign nodes (mean $2.5 \pm 1.37)(P$ value $<0.001)$ (Fig. 2b).

By applying a ROC curve analysis of Emax and Eratio, the true positive rate (sensitivity) was plotted against the false-positive rate (specificity) (AUC for
Emax $=0.880$, AUC for Eratio $=0.902)$, it was found that the best cut-off point for Emax is 59.3, while that for Eratio is 4.56 (Fig. 3).

When considering the calculated cut-off value of Emax which differentiates benign and malignant nodes as 59.3, 28 out of the examined 60 (46.7\%) nodes were diagnosed as benign by Emax, out of which $9(32.1 \%)$ nodes turned out to be malignant by pathology (false negative). On the other hand, 32 out of examined 60 (53.3\%) nodes were considered to be malignant by Emax, out of which 2 (6.25\%) nodes turned out to be benign by pathology (false positive).

When considering the calculated cut-off value of Eratio which differentiates benign and malignant nodes as 4.56 , it was found that 30 out of the examined 60 (50\%) nodes were considered as benign by Eratio, out of which 9 (30\%) nodes were proved to be malignant by pathology (false negative). On another hand, 30 out of the examined 60 (50\%) nodes seemed to be malignant by Eratio, and all of them proved to be truly malignant by pathology (no false positives).

Considering the previous results, sensitivity, specificity, PPV, NPV and accuracy were 76.9, 90.5,93.75, 67.86 and 81.67 respectively, for Emax, with AUC = 0.880 and $P$ value $<0.001$. Those for Eratio were $76.9,100,100,70$ and 85 respectively, with AUC = 0.902 and $P$ value $<0.001$.

\section{Analysis of axillary nodes according to SE The distribution of nodes according to the colour-coded map score (qualitative analysis)}

Five out of the examined 60 nodes had a score of 1 $(8.3 \%)$ (almost all red or green), 10 had a score of 2 (16.7\%) (red > 50\%), 29 had a score of $3(8.3 \%)$ (blue $>50 \%$ ), and 16 had a score of 4 (26.7\%) (almost all blue). Considering scores 1 and 2 as benign descriptors and scores 3 and 4 as malignant ones, the calculated sensitivity and specificity were $92.31 \%$ and $57.14 \%$, whereas the PPV, the NPV and the overall accuracy were $80 \%$ each, if correlated to the final pathology results, with a significant $P$ value $<0.001$ (Table 4).

Table 4 Relation between the qualitative SE results and the final pathology

\begin{tabular}{|c|c|c|c|c|c|c|}
\hline & & \multicolumn{5}{|c|}{ Final pathology } \\
\hline & & \multicolumn{2}{|c|}{ Malignant } & \multicolumn{2}{|l|}{ Benign } & \multirow[t]{2}{*}{$P$ value } \\
\hline & & Number & $\%$ & Number & $\%$ & \\
\hline \multirow{2}{*}{$\begin{array}{l}\text { Color map } \\
\text { score }\end{array}$} & Malignant & 36 & $92.3 \%$ & 9 & $42.9 \%$ & \multirow[t]{2}{*}{$<0.001$} \\
\hline & Benign & 3 & $7.7 \%$ & 12 & $57.1 \%$ & \\
\hline
\end{tabular}


a

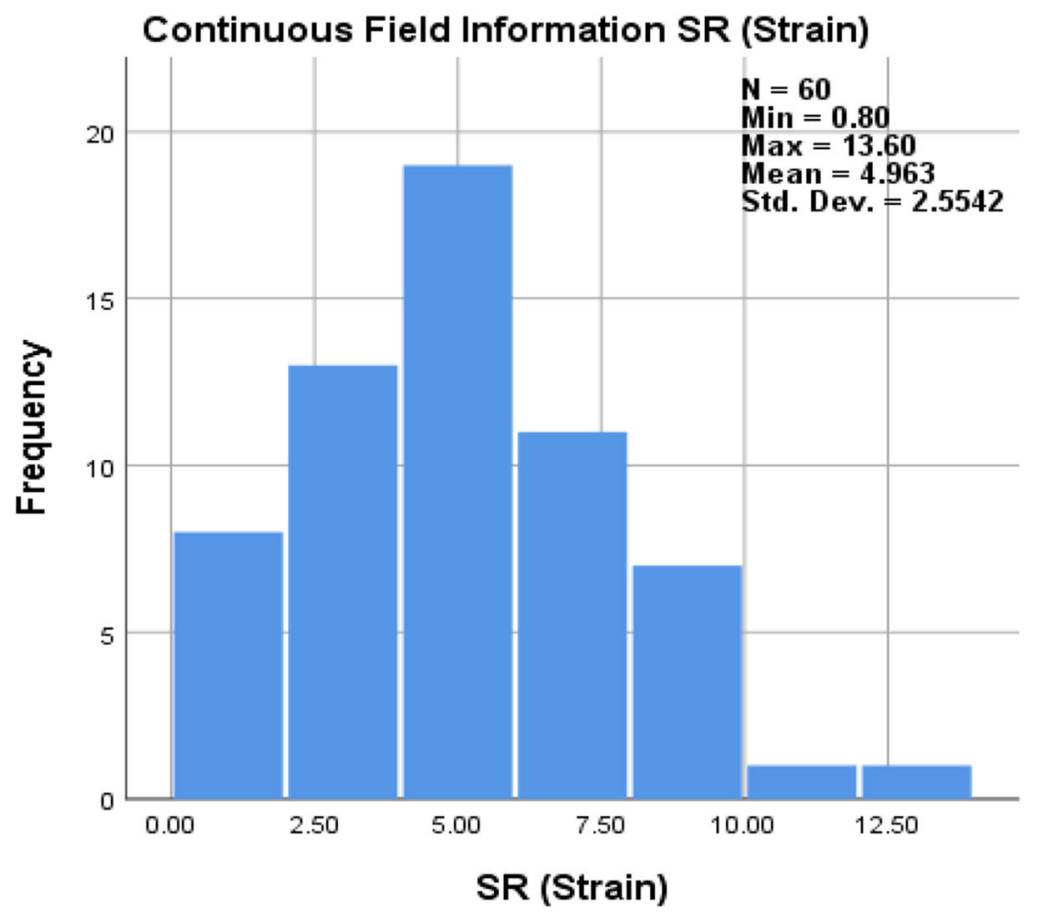

b Independent-Samples Mann-Whitney U Test

FINAL PATHOLOGY

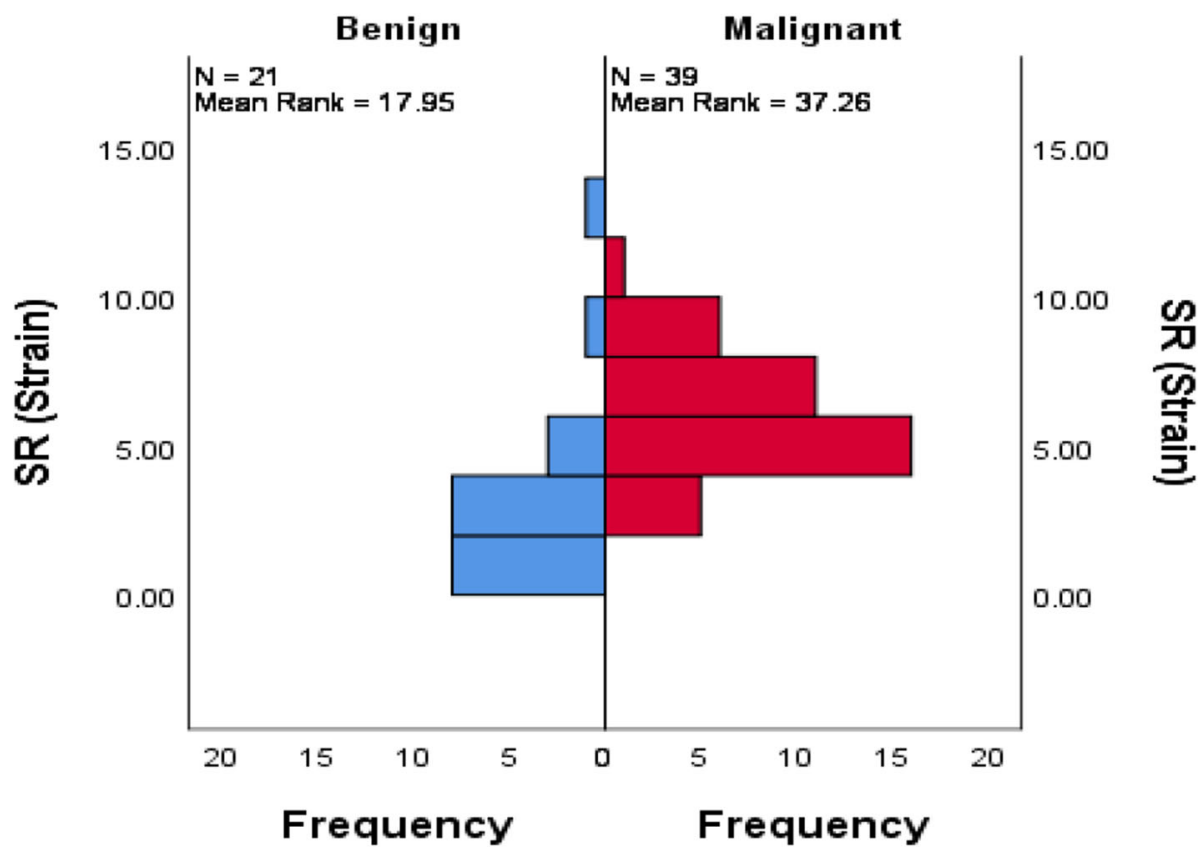

Fig. 4 a Distribution of SR values for the examined nodes. $\mathbf{b}$ Distribution of SR values for benign and malignant nodes 


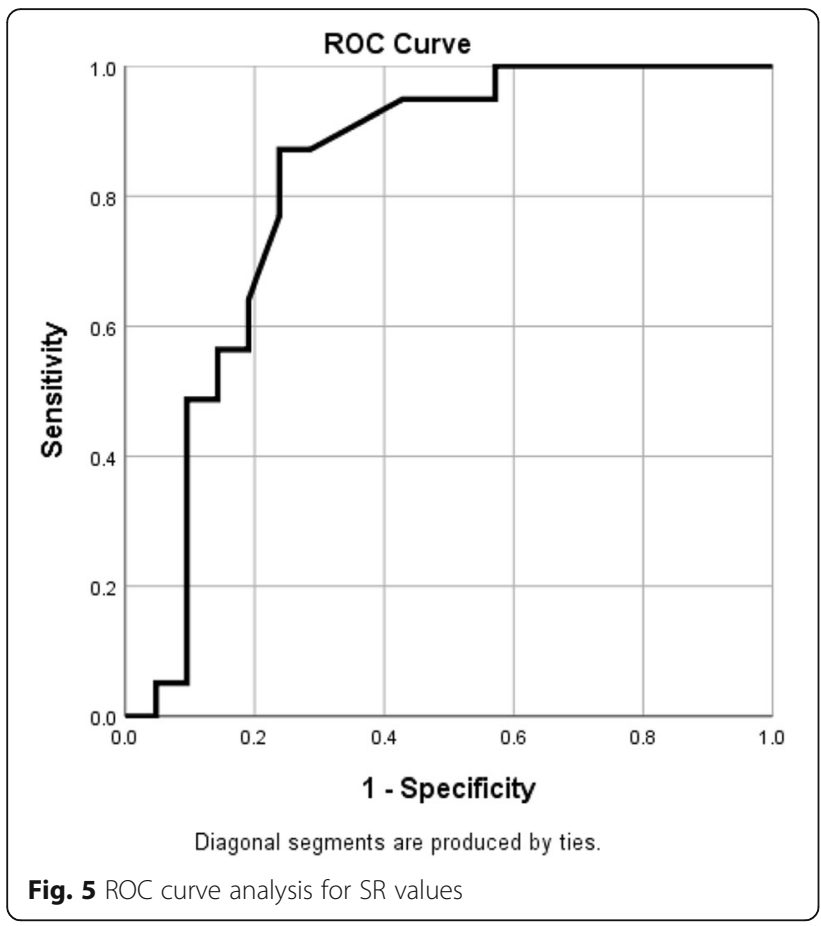

Elastography evaluation of the indeterminate node group diagnosed by b-mode US The US-diagnosed indeterminate group of lymph nodes were evaluated using each modality separately, with correlation to the final pathology results. It was noted that from the examined 60 nodes, $23(38.3 \%)$ were categorized by US as indeterminate, out of which $7 / 23$ (30.4\%)

The distribution of nodes according to $S R$ values

The obtained SR values for all examined nodes ranged from 0.56 to 24.8 (mean $6.69 \pm 5.58$ ). It was found that mean SR values for malignant nodes $(5.76 \pm 1.85)$ were greater than those for benign ones (mean $3.48 \pm 3.03)(P$ value $<0.001)$ (Fig. 4).

By applying ROC curve analysis (Fig. 5) for the obtained SR values (AUC $=0.822$ ), it was found that the best cut-off point that differentiates benign from malignant nodes was 3.85 . By applying this cut-off value, 21 out of the examined $60(35 \%)$ nodes were considered as benign by SR, out of which $5 / 21$ (23.8\%) turned out to be malignant by pathology (false negative), and 39 out of the examined 60 (65\%) nodes were considered as malignant by SR, out of which 5/39 (12.8\%) turned out to be benign by pathology (false positive) (Figs. 6 and 7).

This resulted in $87.2 \%$ sensitivity, $76.2 \%$ specificity, 76.19\% NPV, 87.18\% PPV and 83.33\% accuracy.
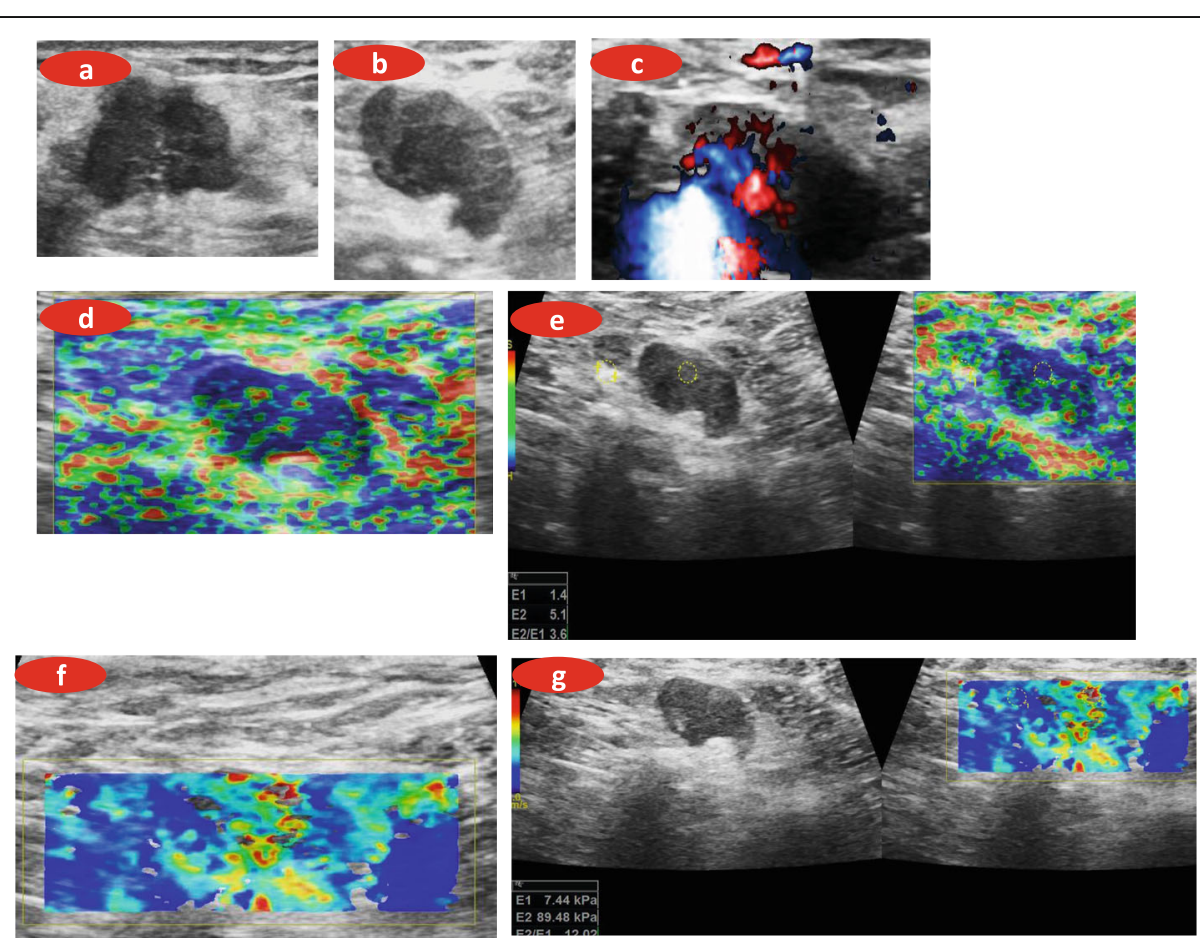

Fig. 6 A pregnant 33-year-old lady presenting with a palpable breast lump 


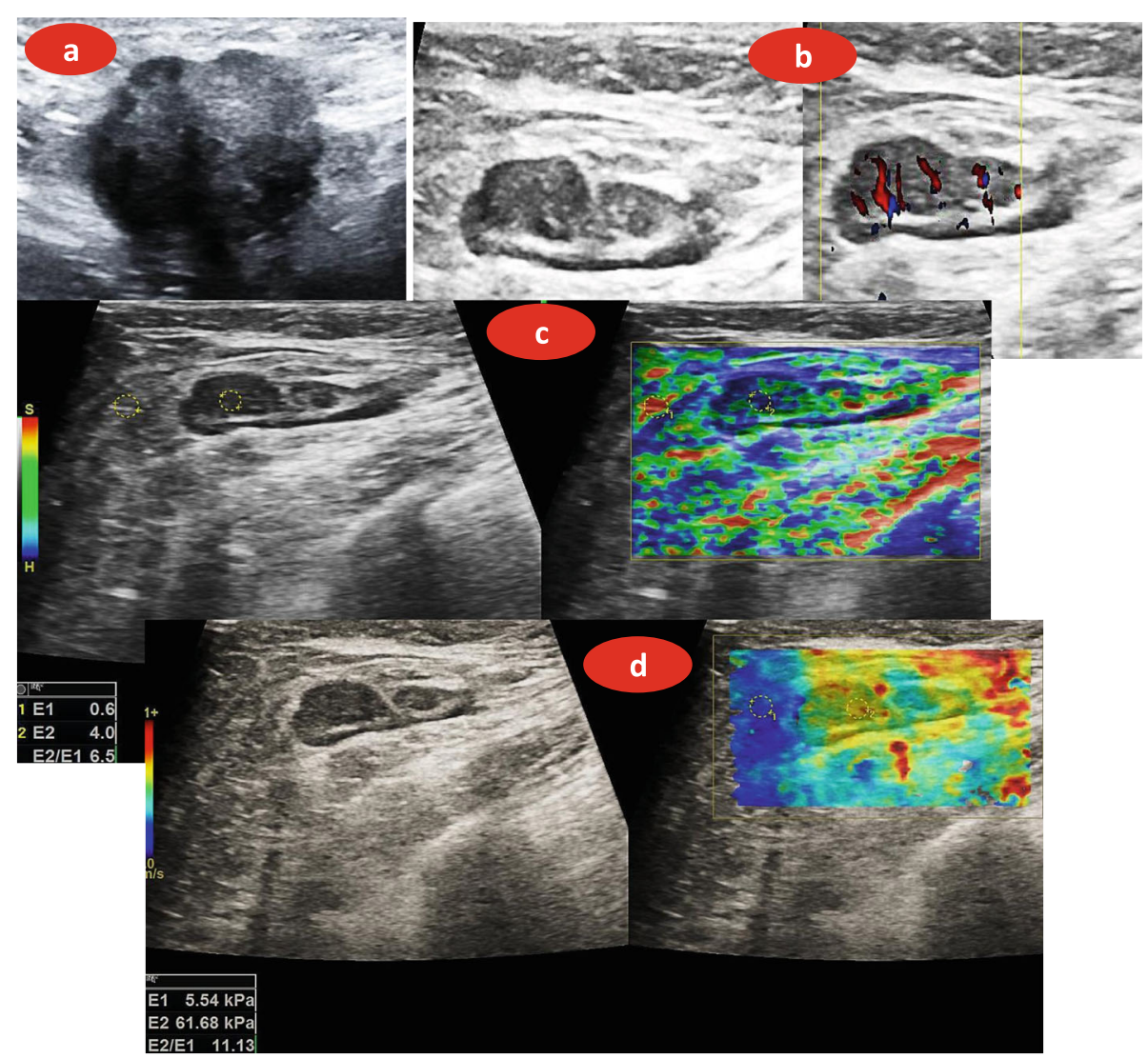

Fig. 7 A 28-year-old lady with palpable left breast lump

were pathologically proven benign (false positive), and $16 / 23(69.6 \%)$ were pathologically proven malignant (true positive).

Using SR of SE changed the diagnosis of $4 / 23$ indeterminate nodes from malignant (false positive by US) into benign (true negative by SR), which were confirmed to be truly benign by pathology (Fig. 8), having sensitivity, specificity, PPV, NPV and accuracy of $75 \%$, $57.14 \%, 80 \%, 50 \%$ and $69.57 \%$ respectively, with significant $P$ value $<0.001$.

Using Emax of SWE changed the diagnosis of 5/23 indeterminate nodes from malignant (false positive by US) into benign (true negative by Emax), which were confirmed benign by pathology (Fig. 9). Sensitivity, specificity, PPV, NPV and accuracy were 50\%, 71.43\%, $80 \%, 38.46 \%$ and $56.52 \%$ respectively, with a significant $P$ value $<0.001$.

On the other hand, using Eratio of SWE, changed the diagnosis of $7 / 23$ indeterminate nodes from malignant (false positive by US) into benign (true negative by Eratio), which were confirmed benign by pathology, with sensitivity, specificity, PPV, NPV and accuracy of
$56.25 \%, 100 \%, 100 \%, 50 \%$ and $69.57 \%$ respectively, with significant $P$ value $<0.001$.

The diagnostic indices of the different imaging modalities used in the study are shown in Table 5.

\section{Discussion}

Accurate diagnosis of the axillary nodal status in cases of newly discovered breast cancer is important for proper management [1]. Imaging is an integral part of preoperative axillary staging, commonly achieved by US and US-guided sampling. In-essential sentinel nodal sampling may result in morbidity of the ipsilateral limb, which justifies the importance of increasing the accuracy of non-invasive, preoperative nodal evaluation [2].

Elastography can potentially differentiate malignant from benign tissue, via measuring its stiffness. It can increase accuracy and specificity of US evaluation [3].

In this study, we studied the additional value of adding SE or SWE to axillary US evaluation of 60 female patients who were recently diagnosed with breast cancer and scored either BIRADS 4 or 5 on SMG. 


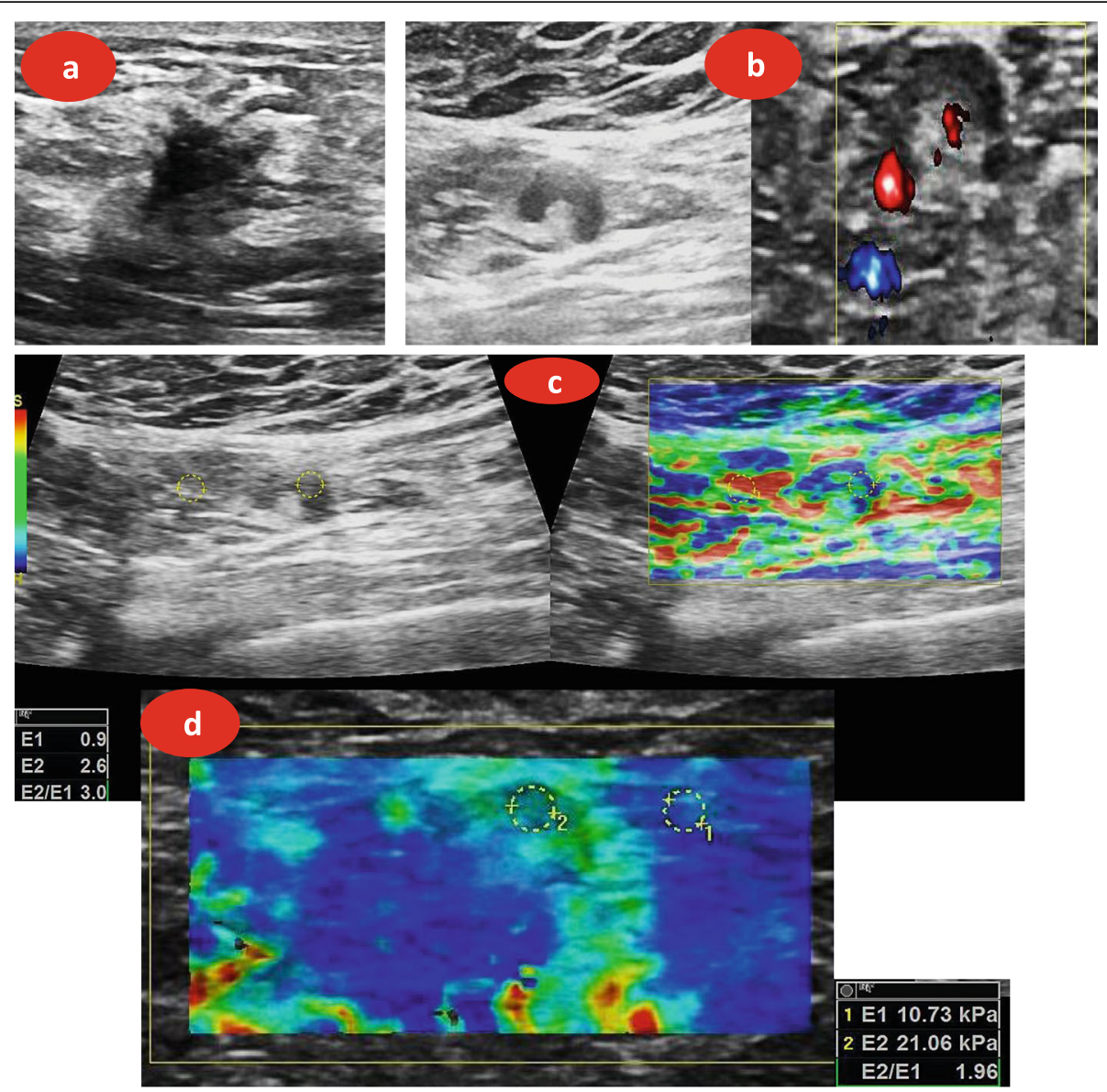

Fig. 8 A 48-year-old lady with a palpable right breast lump

Each node was classified by conventional US as either benign, indeterminate or malignant blinded to histopathology results. The US-diagnosed indeterminate group of nodes was added to the malignant group and were all together considered as suspicious (malignant). This resulted in a rather higher figure of US sensitivity (100\%) to detect suspicious nodes; however, with relatively lower specificity (66.67\%). Several previous researchers studied the diagnostic value of US evaluation of axillary nodes. These studies include the studies carried out by Riedel et al. [6], Gipponi et al. [7], Marino et al. [8] and Rukanskienè et al. [9].

In the current study, pathology-proven malignant nodes generally showed higher cortical thickening compared to benign ones, where it proved to be the most sensitive criterion for detecting metastatic nodes. However, its specificity was relatively lower as diffuse thickening ( 26 nodes) could be seen with other benign conditions where $2 / 26$ nodes proved to be benign. Moreover, 15 nodes showed focal cortical thickening, out of which 4 were proved benign. These results match those of several other researchers, such as Chang et al. [3] and Abe et al. [10].

Nodal vascular pattern was the second most sensitive US criterion for detecting malignant nodes (79.5\% sensitivity), which agrees with the results of a previous study [3].

It was also noticed that pathology-proven malignant nodes showed effaced, eccentric or totally infiltrated fatty hila if compared with benign ones, which goes in agreement with the results of the study done by Dawoud et al. [11].

Nodal shape was the least sensitive US criterion for detecting infiltration, $(51.28 \%$ sensitivity $)$. Yet, it showed better specificity, as all pathology-proven benign nodes $(21 / 60)$ retained their ovoid shape. This is rather similar to the reported results of few previous studies $[1,3]$.

Regarding SWE in the current study, nodes were evaluated by the colour-coded map scoring (qualitative method) and by both 'Emax' and 'Eratio' (quantitative method). 

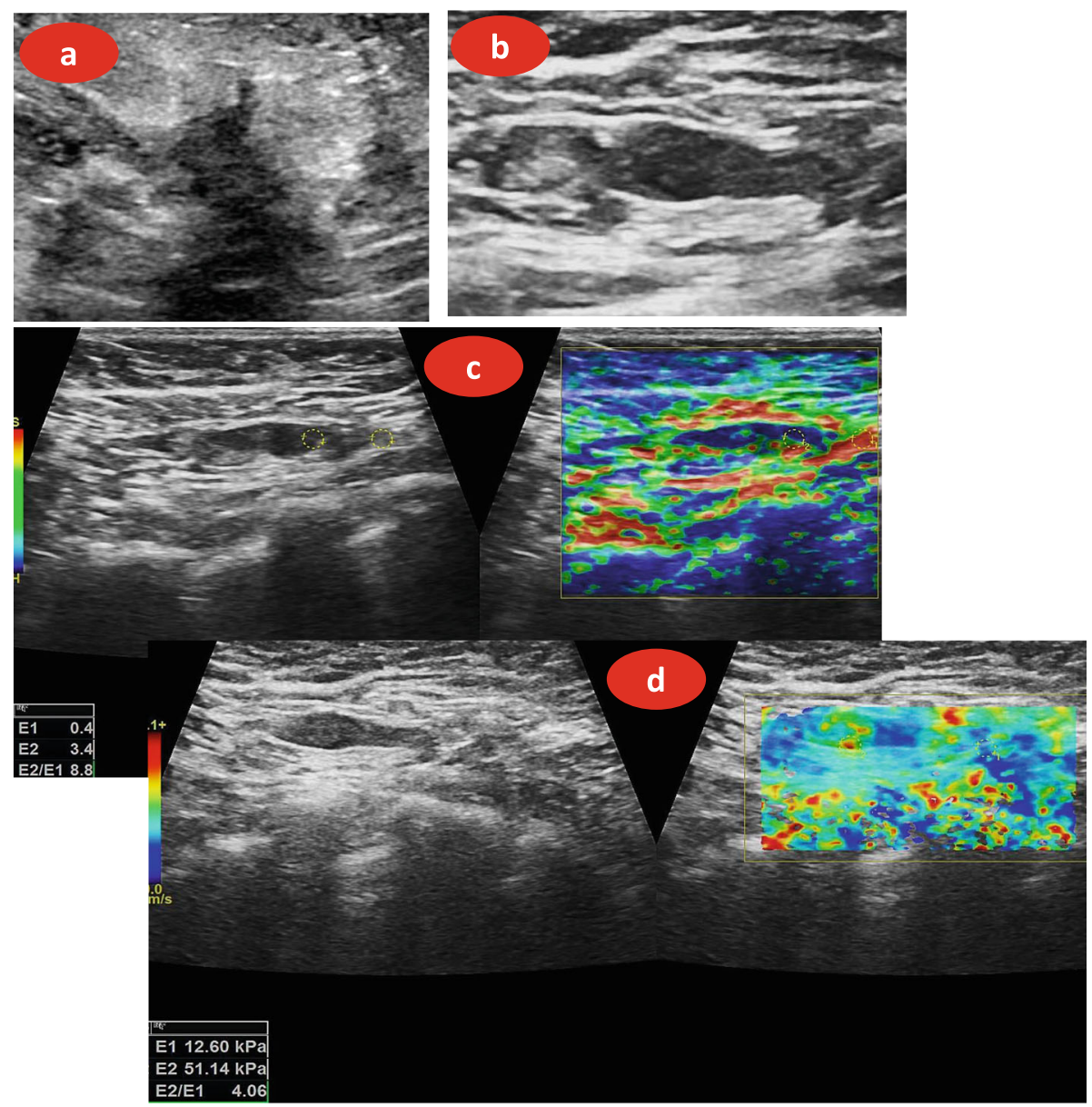

Fig. 9 A 45-year-old lady with positive maternal family history, presenting for screening

For colour-map scoring, the results of the current study showed rather lower statistical indices if compared to the quantitative assessment which showed better statistical performance. These results do not match those of Luo et al. [12] who quoted better performance of the qualitative method, if compared with the quantitative one. This may be attributed to the implementation of a different scoring system in either study.
On the other hand, Eratio values showed higher diagnostic performance indices than those of Emax which agrees with the results of Youk et al. [1].

Both Emax (range 8-156 Kpa, mean $66.3 \pm 36.95$ ) and Eratio (range 0.56-24.8, mean $6.69 \pm 5.58$ ) were generally greater for malignant nodes $(E \max =81.77 \pm 1.904$, Eratio $=8.95 \pm 5.69)$ than for benign ones $($ Emax $=$ $37.59 \pm 33.37$, Eratio $=2.5 \pm 1.37$ ), having significant $P$

Table 5 Diagnostic indices of the different modalities used in the study.

\begin{tabular}{|c|c|c|c|c|c|c|c|c|c|}
\hline Item & TP & FN & $\mathrm{TN}$ & FP & Sensitivity & Specificity & PPV & NPV & Accuracy \\
\hline Conventional Ultrasound & 39 & 0 & 14 & 7 & $100 \%$ & $66.67 \%$ & $84.78 \%$ & $100 \% \%$ & $88.33 \%$ \\
\hline Qualitative SWE & 30 & 9 & 17 & 4 & $76.92 \%$ & $80.95 \%$ & $88.24 \%$ & $65.38 \%$ & $78.33 \%$ \\
\hline Emax (SWE) & 30 & 9 & 19 & 2 & $76.9 \%$ & $90.5 \%$ & $93.75 \%$ & $67.86 \%$ & $81.67 \%$ \\
\hline Eratio (SWE) & 30 & 9 & 21 & 0 & $76.9 \%$ & $100 \%$ & $100 \%$ & $70 \%$ & $85 \%$ \\
\hline Qualitative SE & 36 & 3 & 12 & 9 & $92.31 \%$ & $57.14 \%$ & $80 \%$ & $80 \%$ & $80 \%$ \\
\hline SR (SE) & 34 & 5 & 16 & 5 & $87.2 \%$ & $76.2 \%$ & $87.10 \%$ & $76.19 \%$ & $83.33 \%$ \\
\hline
\end{tabular}




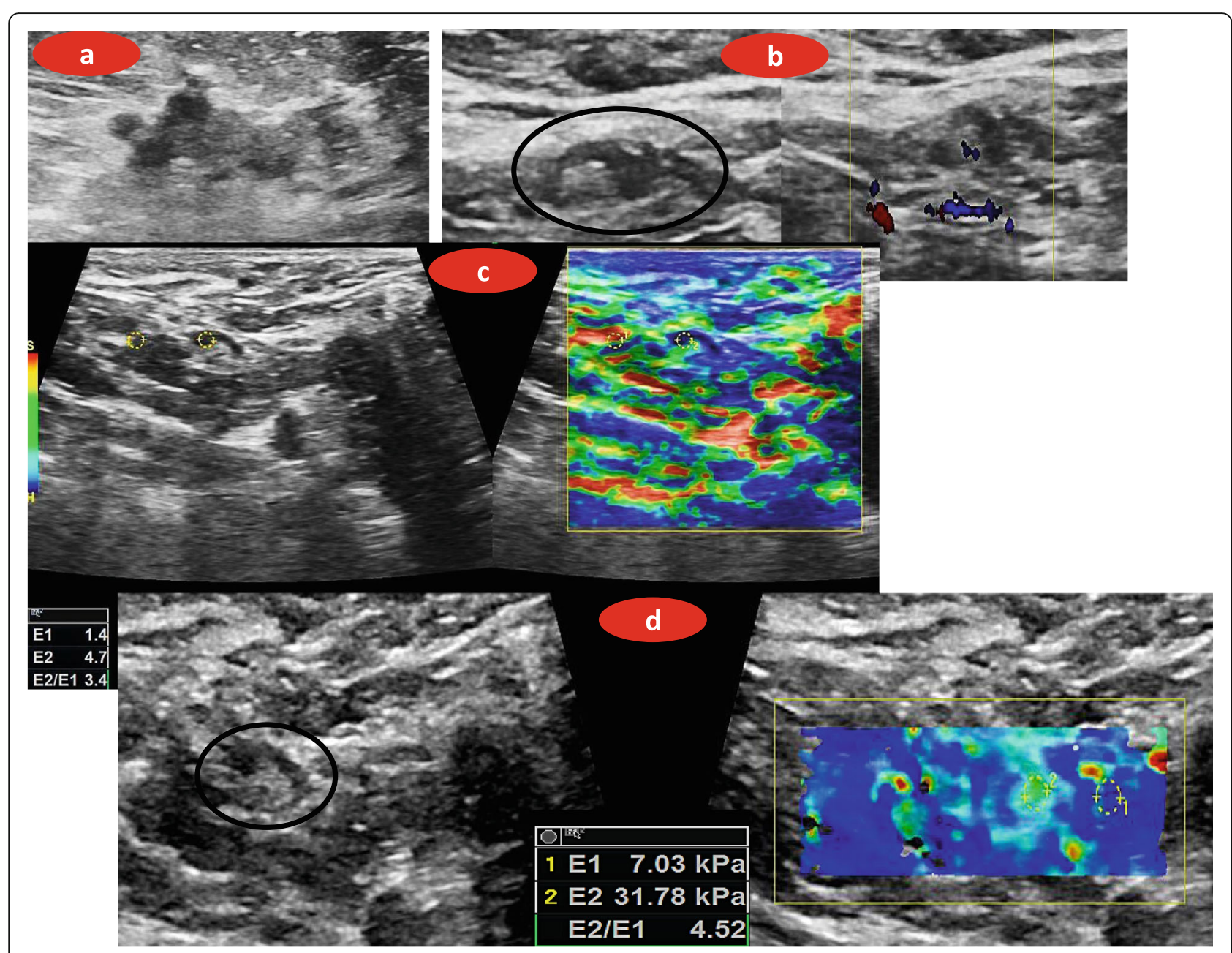

Fig. 10 A 45-year-old lady presenting with a palpable right breast lump

values $<0.001$. This agrees with those of several other studies $[13,14]$.

Regarding SE, all nodes included in the current study were evaluated by colour-coded map scoring (qualitative) and strain ratio (SR) (semi-quantitative).

For colour-coded map scoring of SE, a scoring system based on the percentage of hard portions within a node was used, where if those hard portions represented more than $50 \%$, this node was considered as positive for malignancy. A similar scoring system was used by Chang et al. [3] (Figs. 10 and 11).

On the other hand, SR values were significantly higher for metastatic axillary nodes (mean $5.76 \pm 1.85$ $\mathrm{SD})$ than for non-metastatic ones (mean $3.48 \pm 3.03$ SD; $P$ value $=0.001$ ), with a calculated cut-off value of 3.85. These results are similar to those of several other studies [4, 15].

Comparing the different modalities used in the current study, it was noticed that conventional US had the highest sensitivity (100\%) and accuracy (88.33\%), however with lower specificity (66.67\%). Elastography had better specificity, but less sensitivity which matches the results of $\mathrm{Xu}$ et al. [3]. It can be concluded that elastography, either SWE or SE, is a non-invasive technique that can be added to the preoperative axillary evaluation of patients with recently discovered breast cancer. It can add better specificity to axillary characterization, which agrees with the results of several previous studies [12-14, 16, 17].

\section{Limitations}

One of the limitations of the current study is including only the most suspicious node on the ipsilateral side of the primary tumour and correlating it to the results of histopathology.

Another limitation of this study was combining both the US-considered indeterminate and malignant groups together, to form a suspicious group. In this way, any 


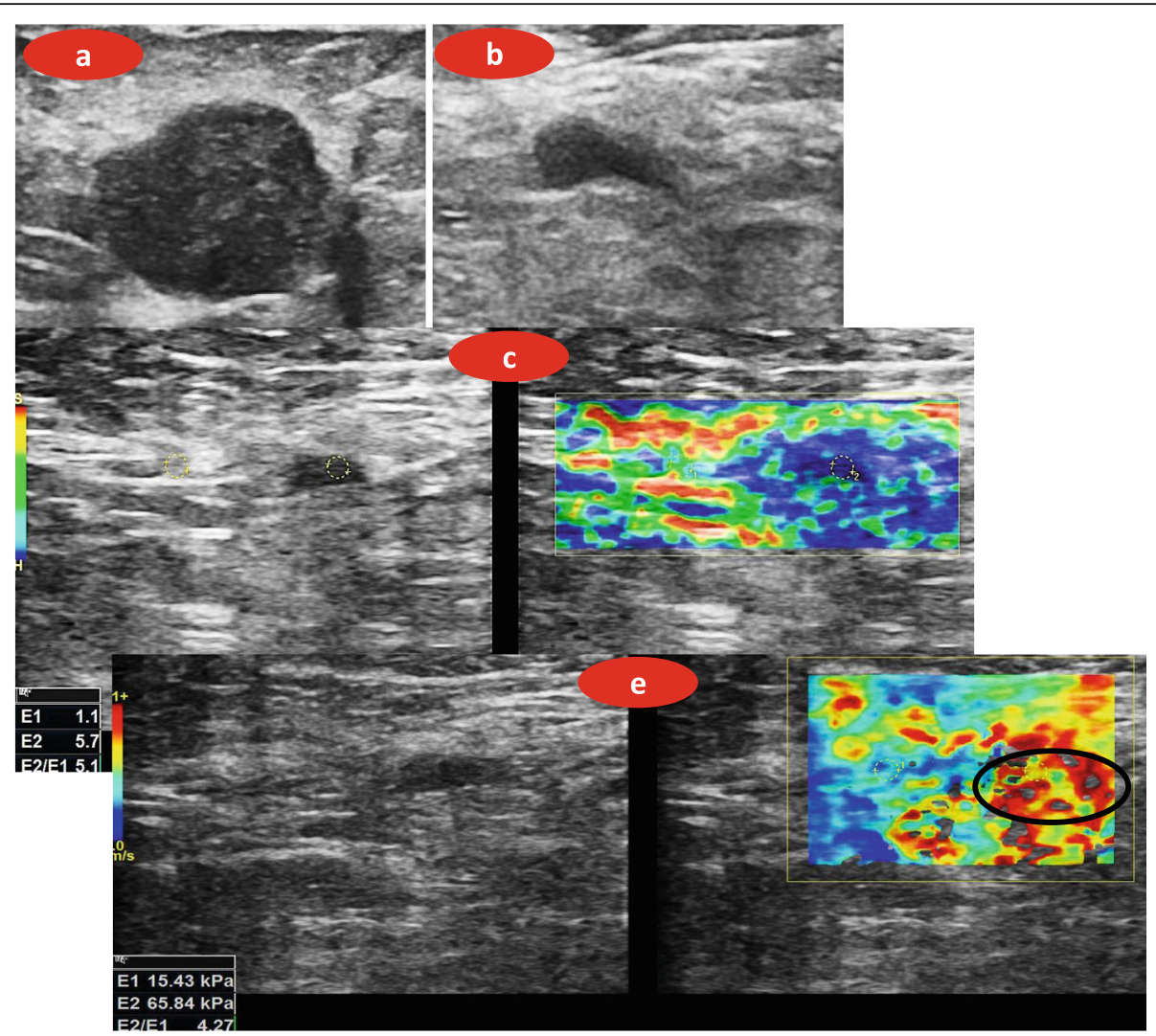

Fig. 11 A 55-year-old lady with a palpable left breast lump

lymph node that had any off-classic criteria was considered in the suspicious group which may account for the higher figure of sensitivity of US and relatively lower specificity.

We were also faced with problems concerning the optimal extent of compression of tissues that affects elasticity images and scores, which needs experience with the technique in order to get reproducible results. It was noticed that Eratio figures were the least affected by this difference as shear wave values equally change in both a lesion and its surroundings.

\section{Conclusion}

Precise evaluation of the axillary status in patients with newly diagnosed breast cancer is crucial for accurate management. Conventional axillary US is highly sensitive for the detection of abnormal axillary nodes, yet its specificity can be augmented by combining it with elasticity evaluation which reflects on decreasing the number of diagnosed indeterminate nodes. This can help in eliminating under or over staging of the axillary status in each patient which can lead to better tailoring of management selection. Elastography is a non-invasive additional tool that can be added to preoperative ultrasound nodal evaluation in order to increase the diagnostic confidence. However, as it still presents variable diagnostic performance, further standardisation of techniques is required to give reproducible results.

\section{Abbreviations}

AUC: Area under the curve; BIRADS: Breast Imaging Reporting Database System Score; Emax: Maximum elasticity calculated using pressure wave velocity in the examined region; Eratio: Ratio between nodal mean elasticity and its surroundings; NPV: Negative predictive value; PPV: Positive predictive value; ROC curve: Receiver operating characteristic curve; ROI: Region of interest; SD: Standard deviation; SE: Strain elastography;

SMG: Sonomammography; SR: Strain ratio; SWE: Shear wave elastography; US: Ultrasound

\section{Acknowledgements}

No acknowledgements.

\section{Authors' contributions}

DE wrote the manuscript. ME collected patient data. LH worked on image processing and collection of patient images. SH participated in the design of the study and performed the statistical analysis. ON and DE conceived the study and participated in its design and coordination and helped to draft the manuscript. SH was responsible of revision of the draft from clinical point of view. OY collected the clinical and pathological data. The authors have read and approved the manuscript.

Funding

There are no funding sources. 


\section{Availability of data and materials}

The datasets used and analyzed during the current study are available from the corresponding author on reasonable request.

\section{Declarations}

\section{Ethics approval and consent to participate}

The study was approved by the ethical committee of "Faculty of medicine, Cairo University" with ethical committee approval number and date not available. An informed written consent was taken from all subjects.

\section{Consent for publication}

All patients included in this research gave written informed consent to publish the data contained within this study.

\section{Competing interests}

The authors declare that they have no financial or non-financial competing interests.

\section{Author details}

${ }^{1}$ Department of Diagnostic and Interventional Radiology, Faculty of Medicine, Cairo University, Cairo, Egypt. ${ }^{2}$ Department of Diagnostic and Interventional Radiology, Baheya Foundation, Cairo, Egypt. ${ }^{3}$ Department of Surgical Oncology, National Cancer Institute, Faculty of Medicine, Cairo University, Cairo, Egypt. ${ }^{4}$ Department of Diagnostic and Interventional Radiology, National Cancer Institute, Faculty of Medicine, Cairo University, Cairo, Egypt.

Received: 17 May 2021 Accepted: 7 July 2021

Published online: 20 July 2021

\section{References}

1. Youk JH, Gweon HM, Son EJ (2017) Shear-wave elastography in breast ultrasonography: the state of the art. Ultrasonography 36(4):300-309. https://doi.org/10.14366/usg.17024

2. Hafiz A, Adeniji-Sofoluwe AT, Ademola AF, Obajimi MO (2018) Sonographic evaluation of axillary lymph nodes in women with newly diagnosed breast cancer at the university college hospital Ibadan, Nigeria. Niger Postgrad Med J. 25(2):79-86. https://doi.org/10.4103/ npmj.npmj_74_18

3. Chang W, Jia W, Shi J, Yuan C, Zhang Y, Chen M (2018) Role of elastography in axillary examination of patients with breast cancer. JUM 37(3):699-707. https://doi.org/10.1002/jum.14538

4. Xu Y, Bai X, Chen Y, Jiang L, Hu B, Hu B, Yu L (2018) Application of real-time elastography ultrasound in the diagnosis of axillary lymph node metastasis in breast cancer patients. Sci Rep. 8(1):10234. https://doi.org/10.1038/s41598018-28474-y

5. Imtiaz S (2018) Breast elastography: a new paradigm in diagnostic breast imaging. Appl Radiol. 47(3):14-19

6. Riedel F, Schaefgen B, Sinn HP, Feisst M, Hennigs A, Hug S, Binnig A, Gomez C, Harcos A, Stieber A, Kauczor HU, Sohn C, Golatta M, Glaeser A, Heil J (2020) Diagnostic accuracy of axillary staging by ultrasound in early breast cancer patients. Eur J Radiol. 135:109468. https://doi.org/10.1016/j.ejrad.202 0.109468

7. Gipponi M, Fregatti P, Garlaschi A, Murelli F, Margarino C, Depaoli F, Baccini P, Gallo M, Friedman D (2016) 'Axillary ultrasound and fineneedle aspiration cytology in the preoperative staging of axillary node metastasis in breast cancer patients. Breast. 30:146-150. https://doi.org/1 0.1016/j.breast.2016.09.009

8. Marino MA, Avendano D, Zapata P, Riedl C, Pinker K (2020) Lymph node imaging in patients with primary breast cancer: concurrent diagnostic tools. Oncologist. 25(2):e231-e242. https://doi.org/10.1634/ theoncologist.2019-0427

9. Rukanskienė $D$, Veikutis $V$, Jonaitienė $E$, Basevičiūtè $M$, Kunigiškis $D$, Paukštaitienè R, Čepulienè D, Poškienè L, Boguševičius A (2020) Preoperative axillary ultrasound versus sentinel lymph node biopsy in patients with early breast cancer. Medicina (Kaunas). 56(3):127. https://doi.org/10.3390/medicina 56030127

10. Abe H, Schmidt RA, Kulkarni K, Sennett CA, Mueller JS, Newstead GM (2009) 'Axillary lymph nodes suspicious for breast cancer metastasis: sampling with US-guided 14-gauge core-needle biopsy-clinical experience in 100 patients. Radiol. 250(1):41-49. https://doi.org/10.1148/ radiol. 2493071483

11. Dawoud M, Nagy H, Allam A (2018) 'Role of strain elastosonography, B mode and color duplex ultrasonography in differentiation between benign and malignant axillary lymph nodes. EJRNM 49(2):485-491. https://doi.org/1 0.1016/j.ejrnm.2018.02.008

12. Luo S, Yao G, Hong Z, Zhang S, Wang W, Zhang J, Zhang Y, Wu J, Zhang L, Cheng H, Hao Y, Li Y (2019) Qualitative classification of shear wave elastography for differential diagnosis between benign and metastatic axillary lymph nodes in breast cancer. Front Oncol. 9:533. https://doi.org/1 0.3389/fonc.2019.00533

13. Bae SJ, Youk JH, Yoon Cl, Park S, Cha CH, Lee HW, Ahn SG, Lee SA, Son EJ, Jeong J (2020) A nomogram constructed using intraoperative ex vivo shear-wave elastography precisely predicts metastasis of sentinel lymph nodes in breast cancer. Eur Radiol. 30(2):789-797. https://doi.org/10.1007/s00330-019-06473-5

14. Wang RY, Zhang YW, Gao ZM, Wang XM (2020) Role of sonoelastography in assessment of axillary lymph nodes in breast cancer: a systematic review and meta-analysis. Clin Radiol 75(4):320.e1-320.e7. https://doi.org/10.1016/j. crad.2019.11.016

15. Choi J, Kang BJ, Kim SH, Lee JH, Jeong SH, Yim HW, Song BJ, Jung SS (2011) Role of sonographic elastography in the differential diagnosis of axillary lymph nodes in breast cancer. J Ultrasound Med. 30(4):429-436. https://doi. org/10.7863/jum.2011.30.4.429

16. Tang GX, Xiao XY, Xu XL, Yang HY, Cai YC, Liu XD, Tian J, Luo BM (2020) Diagnostic value of ultrasound elastography for differentiation of benign and malignant axillary lymph nodes: a meta-analysis. Clin Radiol 75(6):481. e9-481.e16. https://doi.org/10.1016/j.crad.2020.03.021

17. Seo M, Sohn YM (2018) Differentiation of benign and metastatic axillary lymph nodes in breast cancer: additive value of shear wave elastography to B-mode ultrasound. Clin Imaging. 50:258-263. https://doi.org/10.1016/j. clinimag.2018.04.013

\section{Publisher's Note}

Springer Nature remains neutral with regard to jurisdictional claims in published maps and institutional affiliations.

\section{Submit your manuscript to a SpringerOpen ${ }^{\circ}$ journal and benefit from:}

- Convenient online submission

- Rigorous peer review

- Open access: articles freely available online

- High visibility within the field

- Retaining the copyright to your article

Submit your next manuscript at $>$ springeropen.com 